\title{
In Search for Implementing Learning-Oriented Assessment in an EFL Setting
}

\author{
Holi Ibrahim Holi Ali ${ }^{1, *}$ \\ ${ }^{1}$ Department of English Language \& Literature (DELL), Rustaq College of Applied Sciences, Rsutaq, Oman \\ *Correspondence: Rustaq College of Applied Sciences, Department of English Language \& Literature (DELL), \\ Rsutaq, Oman. E-mail: howlli2@yahoo.com
}

Received: Septpember 27, 2013

Accepted: October 25, 2013 Online Published: November 19, 2013

doi:10.5430/wjel.v3n4p11

URL: http://dx.doi.org/10.5430/wjel.v3n4p11

\begin{abstract}
Learning-oriented assessment (LOA) is a kind of assessment which is used to promote and stimulate learning, and improve instruction and teaching. Learning-oriented assessment is viewed as crucial to language assessment. Therefore, this paper is an attempt to explore whether teachers support the notion of using LOA in an ELF setting or not ,why do teacher support the use of it, how can LOA be implemented, and what are the possible challenges that might be encountered in implementing LOA. 25 teachers were surveyed to answer the six open-ended questions raised by the study. The findings showed that all teachers are in favour of LOA and they support its use and implementation because they believed that it could help learners to learn better and promote active learning. They believed that the best way for implementing LOA is through training both of teachers and students in using self-evaluation, peer-assessment and portfolio assessment techniques and principles. Moreover, assessment tasks should be made as learning tasks and should be well-aligned with the curriculum objectives and goals, and timely feedback should be given to students to scaffold their learning.
\end{abstract}

Keywords: learning-oriented assessment; foreign language assessment; EFL setting; assessment for learning (AFL); assessment of learning $(\mathrm{AOL})$

\section{Introduction}

\subsection{Rationale}

Assessment in tertiary education is of utmost importance because it "serves multiple purposes such as providing information about student learning, student progress, teaching quality, and programme and institutional accountability" (Fletcher, et al., 2012, p.119). Assessing student performance is one of the most important activities educators undertake (Ellington1999; Trotter 2006 cited in Craddock \& Mathias, 2009). "English language learners have a variety of goals, and assessment should determine if these goals have been met" or not (Green \& Andrade, 2010, p.322). Relevant literature on assessment over many years with regard to the principles and best guidelines for higher education assessment was compiled to ensure that graduates master critical academic and professional outcomes (Banta et al. 2002; Chikering \& Gamson 1987; Hounsell et al. 1996; Maki 2004; Trigwell \& Prosser 1991 cited in Fletcher, 2011). However, there are many challenges which face assessment in higher education (Careless, 2007, p.57). One of these challenges is the dominance of summative evaluations which is in 'disarray' in terms of reliability in measuring higher education complex learning outcomes (Knight, 2002 cited in Careless, 2007). Furthermore, Boud (1995) asserts that one of the fundamental challenges that face assessment is its ability to stimulate the right kind of learning. What and how learners learn depends to a major extent on how they think they will be assessed. Assessment practice must send the right message to student about what they should be learning and how they should be learning it (Biggs \&Tang, 2007, p.163). Currently, most higher education institutions use the two common different models which are summative assessment models which may send the wrong signal to both students and teachers about their learning and teaching. This paper argues that current assessment practice in the Department of English Language and Literature (DELL) could not help attain the expected learning outcomes and equip students with effective learning. So, teachers' views and theories of teaching and learning concerning what must be learned influence their conceptions of assessment, what they choose to assess, and how they assess student 
learning outcomes (Watkins et al . 2005). Therefore, learning-oriented assessment is of paramount importance and should be used to support effective learning. Learning-oriented assessment is a kind of formative assessment operates to improve learning of and teaching (p.163). If assessment is appropriately configured could be a positive force which promote student learning in productive ways and directions (Carless, 2009). Therefore, the aim of the paper is to emphasize the importance of learning-oriented assessment and it seeks to address the issue of whether teachers support the idea of using LOA, why the support it use, and how can LOA framework be implemented in the Department of English Language and Literature (DELL) at Rustaq College of Applied Sciences in the Sultanate of Oman. The LOA conceptual framework has three strands which should be applied in the DELL to further improve assessment practices. These strands which are: assessment tasks should be learning tasks, students student be involved in assessment process, and timely feedback should always be given. If these strands are used as whole elements not as discrete ones, effective learning will be promoted and take place.

\subsection{Objectives of the Study}

This study is an attempt to shed light on the principles and implications of learning-oriented assessment in an EFL setting and promote its use through implementing a certain model. The study tries to explore faculty's perspectives about the potential use of learning-oriented assessment model in the DELL. Moreover, the study seeks to find out why do teachers support the idea of using learning-oriented assessment, and find out some ways for implementing it and overcoming the potential challenges which may encountered. Because assessment is usually done to inform student learning and sort them into those who pass and those who fail and measures learning outcomes and compare students' performance to each other (Knight, 2006).

\subsection{Study Questions}

1. To what extent do EFL teachers support the use of learning-oriented assessment in the DELL? Why do they support it?

2. How can learning-oriented assessment be implemented in the DELL?

3. What are the possible challenges in implementing learning-oriented assessment the DELL?

\section{Theoretical Foundations}

\subsection{Defining Learning-Oriented Assessment (LOA)}

Learning-oriented assessment is considered one of the popular tools of "assessment for learning" used in education to promote student learning and scaffold teaching (Ploegh et al. 2009, 102). Learning-oriented assessment deals with the integration of assessment with learning. It is defined as a kind of assessment which "involves the collection and interpretation of evidence about performance so that judgments can be made for further language development" (Purpura, 2004, p.236). Moreover, LOA is a kind of formative assessment which has a normal affiliation with teaching, and learning and which responds to the evolving needs of the learner and addresses the identified learning objectives and helps learners to reach them, and it contributes to effective teaching and learning (Carless, 2007). Black et al. (2004) discussed the notion of assessment for learning (AFL) and they defined it any assessment for which the priority in its design and practice is to promote students. It thus differs from assessment which is designed for accountability, ranking and certification purposes learning. This kind of assessment practices can help learning if it provides information to be used as feedback by both teachers and students. It should also enable students to assess themselves and each other (Black et al., 2004, pp.2-3). It is believed be assessment for learning (AFL) is a central for learning and could help teachers, learners to become independent learners and receive timely feedback from their teachers, school and parents to monitor their kids learning and progress. Assessment process follows seven phases which are: determining assessment goals and objectives, selecting assessment tasks which should reflect the content covered, establishing appropriate scoring rules which can be used for appraisal purposes, administering and executing the assessment, appraising which involves the actual scoring and grading the task performance by the teacher, the learner, or peers, interpreting and valuing scores by interpreting grades and valuing them against the potential standards, and finally giving feedback which should support and guide the learner and indicate his strengths and weakness and provide him with information on how to improve his future performance (Brualdi, 1998; Freeman \& Lewis, 1998; Moskal, 2003; cited in Ploegh, 2012, pp.103-14). Thus learning-oriented assessment can be used following all the above mentioned assessment phases and can promote and scaffold effective learning process.

\subsection{Benefits of Learning-Oriented Assessment}

Learning-oriented assessment is an attempt to emphasize learning elements more than measurement ones (Carless et 
al., 2006). Assessment for learning or learning-oriented assessment is becoming increasingly recognized as crucial to language assessment (Lee \& Coniam, 2013, 34). If this is contrasted with assessment of learning (AOL), which focuses on using assessment to provide judgment of student learning and using assessment information for administration and reporting purposes (Wiliams,(2001). However both of them are important in assessment. Assessment in higher education serves many purposes such as: informing programme selection decisions, determining student progress towards degrees and qualifications, measuring student learning towards attaining graduate profiles, provide information about teaching effectiveness and faculty instructional skills, showing how well students are doing and how they can improve their learning, controlling and assuring quality in learning and teaching and inform learning and teaching process (Boud 1995; Carless et al. 2007; Banta and Associates 2002; Brown et al. 1997; Gibbs 2006; Gibbs \& Simpson, 2004).This study is guided by the idea of Carless learning-oriented assessment framework which views assessment as an integral part of learning with the purpose of providing valuable feedback for learning and enables him/her to monitor their progress and evaluate the effectiveness of learning strategies (Carless, 2003 \& Kim, 2009, Butler \& Winne, 1995, cited in Kim, 2009, p.106). Learning-oriented feedback serves some cognitive functions which including the learner to confirm his understanding of what a task required was correct and helping him to add information to their knowledge when they experience any information gap. Moreover, it helps him to replace some erroneous information with more accurate and reliable ones. Additionally, it helps the learners to restructure their schemata. In addition, learning-oriented assessment feedback serves some effective and metacognitive function. For example, learning-oriented feedback gives learners fundamental information about themselves and this can help them to understand themselves better and make them more aware of their learning (Kim, 2009). Other key principles of assessment for learning (AFL) which related to the learner were identified which. Firstly, leaners have to be actively involved in their learning and AFL can help in achieving this. Secondly, learners need to be engaged in self- and peer-assessment to develop their critical awareness and faculties. Thirdly, learners must be clear of the learning goals and outcomes which they are intending to achieve, and they should know the criteria they are evaluated against and how to improve their work and learning process Jones (2010). To sum, any assessment practices should support student learning in addition to it should serve its traditional function which is measurement (Keppell \& Carless, 2006). Additionally, the key aims for learning-oriented assessment is to promote productive teaching and student learning (Carless, 2009).

\subsection{Learning-Oriented Assessment Framework}

Assessment in higher education is usually help to provide students with feedback about their learning and for certification purposes (Boud \& Falchikov, 2006, pp., 400).Figure 1 below illustrates and summarizes the main aspects and features of learning-oriented assessment which based on a synthesis of relevant literature. Most of the studies are on peer assessment support, as it is considered as one of the key elements of learning-oriented assessment (Kim, 2009, 107). Therefore, this study proposes learning-oriented assessment framework to be implemented to help the EFL leaners to learn better. There are three strands of learning-oriented assessment which should be seen as a unified whole and rather than discrete elements (see Figure, 1). Firstly assessment tasks should be learning tasks and should be focused on learning. Therefore, learning assessment task design is a key and fundamental components of learning-oriented assessment and these tasks should facilitate and promote learning. They should be well-aligned with the objectives and the learning outcomes and assignments are much more preferred than examinations because they are engaging to the students (Biggs \& Tang, 2007; Gibbs; 2006, Carless 2007a; Carless et al. 2006). Additionally, assessment tasks should be more authentic and should reflect real-life application. These kinds of tasks can be carried out through group work or project-based learning (Keppel \& Carless, 2006). Moreover, assessment tasks should motivate learners to produce their best performance and should be aligned with the objectives of the course (Gibbs).Moreover, offering a variety of assessment tools is often recommended for good practice (Craddock \& Mathias, 2009). Secondly, student involvement in the assessment is considered as the second strand of learning-oriented assessment (Falckikov, 2005). Students need to be actively involved in constructing understanding of content and their involvement can facilitate transparency and enhance mutual trust. Students can also be involved in grading each other's work and their own ones (Boud, 1995). Furthermore, student should be involved through portfolio assessment and self-assessment and in identifying, drafting, summarizing and preparing assessment criteria and this would help them to self-monitor their performance and develop their self-evaluation skills (Boud, 2000, Sadler, 2002). Finally, there is closing of feedback loops by giving timely feedback and forward-looking advice and suggestions so as to support student current and future learning. In this regards William (2007) points out that feedback is only feedback if it leads to some current or future student actions which enhance learning. Closing feedback loops means proving feedback which is acted upon by the student to enhance their learning and that the feedback provider is able to identify the extent to which the recipient has acted on it (Hattie \& Timperley, 2007). To 
sum up, learning-oriented assessment seeks to support the reconciliation and integrating formative and summative tensions by focusing on good assessment principles. Having designing appropriate assessment tasks, involving student in assessments, and giving timely feedback which maximizes learning, effective learning will take place. The DELL in Rustaq College of Applied Sciences needs to follow this proposed conceptual framework which can be implemented in its assessment practices. The framework Figure 1: below is adopted from relevant literature and modified to serve the study purpose.

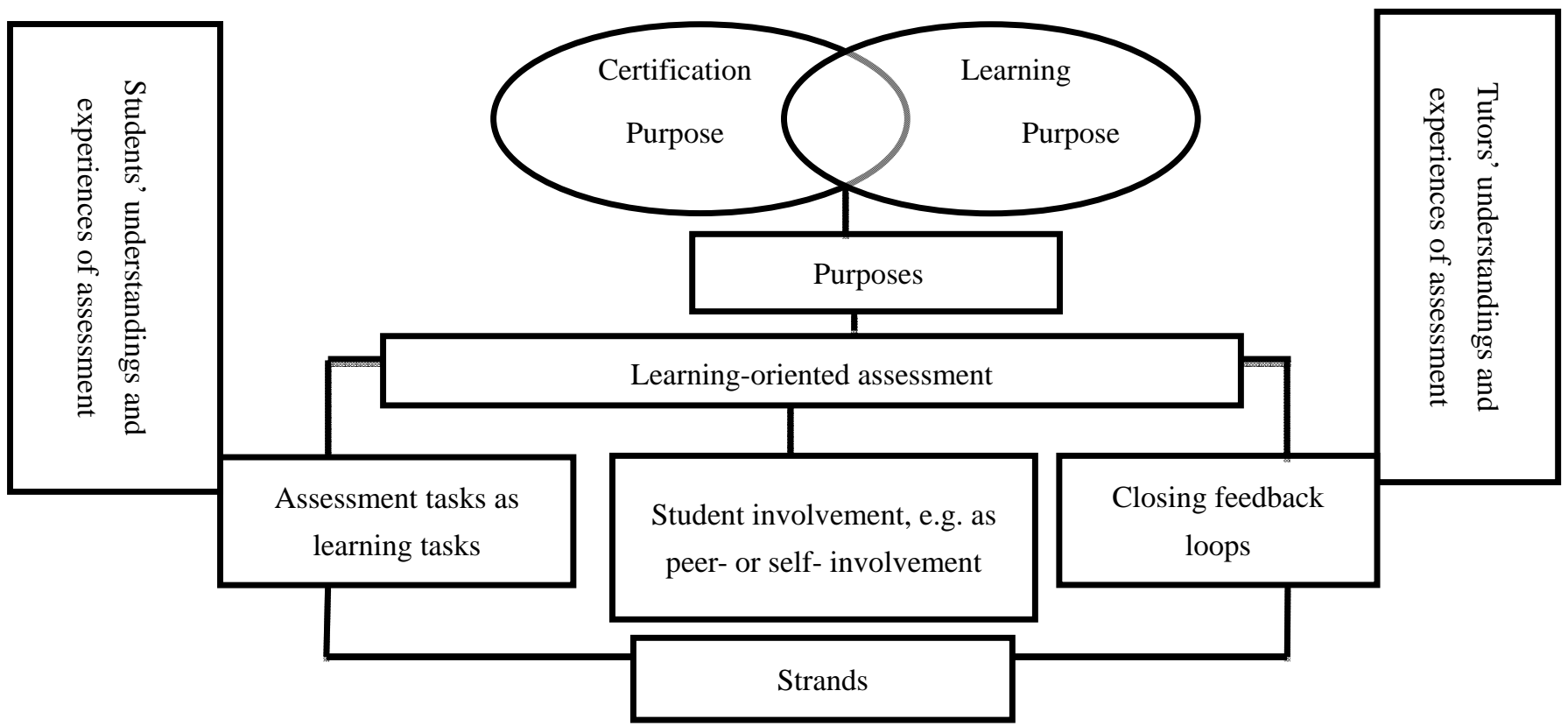

Figure 1: Framework for Learning-Oriented Assessment Adopted from (Carless, 2007a, Carless et al., 2006)

\subsection{Setting}

This study is carried out in a public college in the Sultanate of Oman. They study attempts to explore faculty's views about implementation of learning-oriented assessment with special references to Carless's (2007) framework and other frameworks from existing relevant literature to implement it at the Department of English Language \& Literature (DELL) at Rustaq College of Applied Sciences in Oman. The DELL offers two English language progammes which are: EFL teacher training and foundation programmes. This study an attempt to discover whether teachers support the notion of learning-oriented and assessment or not and why they support it, and how learning-oriented assessment can be implemented, and what are the possible challenges in implementing LOA and how can these challenges be alleviated.

\subsection{Participants}

The participants of this study are made up of 25 EFL/ESL teachers in both a teacher training and foundation programmes in the department of English Language and Literature (DELL) at the Rustaq College of Applied Sciences in the Sultanate of Oman. Teachers are from different countries such as Britain, USA, Philippines, Iran, Syria, India, Sudan, Oman, etc. These teachers have been teaching English language in Oman for a couple of years, and have substantial experience of teaching in the Middle East. The basis for the selection of these teachers in this particular number (25) was their availability and accessibility.

\subsection{Instruments}

This study uses survey which includes open-ended questions given out to $25 \mathrm{EFL} / \mathrm{ESL}$ teachers to generate qualitative data. Of the 25 teachers, 15 of those in the selected samples turned in the survey. The survey comprises six open-ended questions which intended to elicit faculty's responses with regard to learning-oriented assessment, and how can learning-oriented be implemented in this particular college in both foundation and teacher training programmes. 


\subsection{Data Collection, Analysis \& Procedures}

The data was collected via survey distributed to 25 EFL / ESL teachers. It was analyzed using themes that emerged from and were relevant to the research questions which were raised by the study.

\section{Result and Discussion}

The research questions that guided the current investigations were: To what extent do EFL teachers support the use of learning-oriented assessment? Why do teacher support the notion of using learning-oriented assessment? How can learning-oriented assessment be implemented in DELL? What are the possible challenges in implementing learning-oriented assessment DELL?

\subsection{To What Extent do EFL Teachers Support the Use of Learning-Oriented Assessment? Why Do They Support It?}

This question seeks to explore to what extent EFL teachers support the use of learning-oriented assessment in both foundation and ELT programmes in the DELL. All teachers surveyed believed that learning-oriented framework to support student learning in a better way. In response to this question a selection of comments from individual teachers appears below: One teacher said: "I strongly agree with using such type of assessment because this type of assessment will encourage the learners to learn and will lead learners to understand the materials, not memorize them. Especially the in ELT courses which contain theories".

Another teacher said: "Yes, it makes assessment more meaningful for both the teachers and the teachers and students as it reflects learning".

This teacher felt that LOA is important not only for students but also for teachers who look for reflective practice. This is in agreement with (Carless et al., 2006) learning-oriented assessment is important and it attempts to emphasize learning elements more than measurement ones.

Yet another teacher said: "Yes, it is more comprehensive and students can get feedback after learning".

This teacher believed that LOA feedback is significant and this is consistent with Kim (2009) learning-oriented assessment feedback serves some effective and metacognitive function. For example, learning-oriented feedback gives learners fundamental information about themselves and this can help them to understand themselves better and make them more aware of their learning.

Again another teacher reported: "Yes. LOA gives course greater structure and provides the end point focus of a course or subject. This helps the students feel more motivated and goal oriented".

A teacher said: 'Yes, I do support the idea because it seems to be an integrative methods that promotes not only learning outcomes but hands on experience, feedback, but also affords students opportunities to assess themselves".

All teachers surveyed as it appeared in their above comments support the idea of implementing learning-oriented assessment in the DELL as they believed it serves active learning and promotes it.

In response to the other part of the question which is why do teachers support the use of LOA? Several teachers expressed their views about the importance of implementing LOA in the DELL. A teacher argued that learning oriented assessment enables students to use self-evaluation and he believed that "self-evaluation is useful in so far as students review their assessment outcomes after could the assessment have taken place".

Another teacher said: "Yes, because they can share their knowledge and enlighten each other."

Yet one argued that "I don't think it will work. Students might not that responsible and fair in doing assessment".

Another teacher reported that "yes. Students can learn a lot from peers. Self-assessment is also useful in education because it makes students take responsibility of their own learning".

A teacher supported the idea of LOA: [...]"because in this way, the task will be done for the sake of learning instead of a way of evaluating and recording a mark".

Another teacher support the notion of LAO because he believed this type of assessment which uses self-evaluation, and peer assessment "makes students more aware of their weakness and strengths they would know how exactly to improve". This is supported from relevant literature which argues that students need to be actively involved in constructing understanding of content and their involvement can facilitate transparency and enhance mutual trust. Students can also be involved in grading each other's' work and their own ones (Boud, 1995). The great majority of teachers support the use of learning-oriented assessment because they believed that it serves for active learning. All these comments underpin this study attempts to introduce LAO approach to assessment to DELL in order to help 
students to learn better.

\subsection{How Can Learning-Oriented Assessment Be Implemented in DELL?}

There are several potential strategies and suggestions from both relevant literature and teachers which can be incorporated to support the implantation of learning-oriented assessment to improve student learning and quality teaching. One teacher said: learning-oriented assessment can be successfully implemented by "basing the assessment on practical tasks (e.g. micro-teaching, presentations, papers) instead of exams". Self-and peer assessment are important to develop their critical awareness and faculties (Jones, 2010). Another teacher reported: "I think task-based principles should be incorporated into the curriculum. This will lead to having exams with tasks similar to the ones that leaners have already done in classrooms".

Another teacher argued: "By using continuous assessment and grounding theory in reasoning for such assessments". Yet another teacher said: "I think by having continuous assessment during the semester. In addition, changing the assessment from just mi-terms \& final to have another type like asking Ss to do workshops \& T. assesses them using some criteria".

Another teacher said: "1/ first: assessment before placement.2/ methods language build (by implementing an educational plan for the Ss involvement). 3/ reassess, peer-assess, feedback.4/ reteach, recall, relearn. 5/ makes for a successful LOA plan".

A teacher believed that: "self-evaluation and peer-assessment are feedback means by which students' learning and confidence will increase. They are also scaffolds for learning gaps (what Ss need to know about/ or what the lack of understanding in a particular subject)".

The vast majority of teachers believed that LOA can be successfully implemented by involving students through continuous, peer- and self -assessments, and train students and teachers in using them and involving students in preparing assessment criteria and standards. In addition, timely feedback should be given and this is supported by William (2007) who points out that feedback is only feedback if it leads to some current or future student actions which enhance learning, assessment tasks should be made as learning tasks. Furthermore, all previous assessment tools should be reconsidered, and portfolio and projects-based assessment should be used instead of the traditional mode of assessment which relies heavily on exams.

\subsection{What are the Possible Challenges in Implementing Learning-Oriented Assessment DELL?}

Implementing LOA is not as easy task because there are many challenges need to be addressed such as both teachers and students need to be trained in using LOA. As for this question (4), a teacher listed some challenges such as: LOA is "time-consuming, qualified teachers, lack of effective assessment methods and LOA needs a lot of preparation."

Another teacher argued that: 'If learning is to mirror real life events then this might be too "close" to the life experiences of the students who are being taught in this fashion. This could stimulate or discourage learning in a number of ways".

Another teacher reported some challenges which are: "setting criteria for assessment, convincing officials and student of its value, time limitations, and having large groups".

Yet another teacher said: "Actually, I don't see challenges unless the program lacks ability to meet all learning levels, or those assessment criteria do not meet learning needs, of if Ss lack purpose".

A considerable number of teachers argued that there are several challenges in implementing learning-oriented assessment such as time constrains, students and teachers training on LOA principles and guidelines. Overall, the study findings suggest that LOA assessment is in high demand and all the participating teachers are willing to engage in LOA in their current teaching context and they believed that LOA is of utmost importance to them.

\section{Conclusions \& Recommendations}

The aim of this study is to discover teachers' views about the implementation of learning-oriented assessment, and why do teacher support the idea of implementing it in DELL, and how LOA can be implemented and what are the possible challenges in implementing LOA. The themes generated from qualitative data were discussed and suggestions implementing LOA framework were presented. The test reform process within DELL should be done using LOA principles and guidelines to improve assessment practices. The findings showed that all teachers surveyed support the idea of using learning-oriented assessment because they believed that it can promote student learning. 
Additionally, the vast majority of teachers support the idea of LOA for several reasons and they believed that it could help learners to learn better and it can develop their autonomy. Moreover, findings revealed that the most possible ways for implementing learning-oriented assessment is by involving students through projects, self-assessment, peer-evaluation, learning tasks as assessment tasks, and portfolio assessment. Student involvement in assessment is one of the important strands of learning-oriented assessment which can be achieved through peer assessment. As peer assessment is a strong vehicle of assessment for learning because it actively involves students to evaluating their learning and allows them to participate in a collaborative appraisal using multiple perspective when incorporating viewpoints from different learners" (Duchy et al.; 1999; Falchikov, 2005 cited in Ploegh, 2012).

Furthermore, the possible challenges are time constraints, lack of effective assessment tools, and lack of teacher training on LOA, and having large classes. The study recommends that the possible solutions to overcome such challenges are: training teachers on LOA issues, developing learning-oriented assessment tools, involving students in drafting and preparing assessment criteria and guidelines and training them on how to peer-assess and self-evaluate each other. Moreover, assessment tasks should be made as learning tasks, should be well-aligned with the curriculum objectives and goals and feedback should be given a timely manner. The study has several limitations which merit consideration such as the scope, the number of the participants and the number of tools used for data collection.

\section{References}

Ali, I. H.H, \& Al Ajmi, A.A, S. (2013). Towards quality assessment in an EFL programme. English Language Teaching Journal, 6(10), 132-148. http://dx.doi.org/10.5539/elt.v6n10p132

Banta, T., \& Associates. (2002). Building a scholarship of assessment. San Francisco: Jossey-Bass

Biggs, J., \& Tang, C. (2007). Teaching for Quality Learning at University ( $3^{\text {rd }}$ edition). England: Open University Press.

Black et al. (2004).The nature and value of formative assessment for learning. Unpublished manuscript, Educational Testing Service. Princeton, NJ. Retrieved from http://www.kcl.ac.uk/content/1/c4/73/57/formative.pdf

Boud, D. (1995). Enhancing learning through self-assessment. London: Kogan Page.

Boud, D. (2000). Sustainable assessment: Rethinking assessment for learning society. Studies in Continuing Education, 22(2), 151-167.

Boud, D., \& Falchlkov, N. (2006). Aligning assessment with long-term learning. Assessment in Higher Education Journal, 31(4), 399-414. http://dx.doi.org/10.1080/02602930600679050

Brown, G. et al. (1997). Assessing student learning in higher education. London: Routledge.

Carless, D. (2007). Learning-oriented assessment: conceptual bases and practical implications. Journal of Innovations in Education and Teaching International, 44(1), 57-66. http://dx.doi.org/10.1080/14703290601081332

Carless, D. (2009). Trust, distrust and their impact on assessment reform. Assessment and Evaluation in Higher Education, 34(1), 79-89.

Carless, D. et al. (2006). How assessment supports learning: learning-oriented assessment in action. Hong Kong: Hong Kong University Press.

Carless, D. et al. (2007). Learning-oriented assessment: principles and practice. Assessment and Evaluation in Higher Education, 31, 395-398.

Craddock, D., \& Mathias, H. (2009). Assessment options in higher education. Assessment \& Evaluation in Higher Education Journal, 34(2), 127-140. http://dx.doi.org/10.1080/02602930801956026

Ellington, H. (1999). How to teach with excellence. The Times Higher Education Supplement, April 30.

Falchikov, N. (2005). Improving assessment through student involvement. London: Routledge Falmer.

Fletcher, R, B. et al. (2012). Faculty and students conceptions of assessment in higher education. High Education Journal, 64, 119-133. http://dx.doi.org/10.1007/s10734-011-9484-1

Gibbs, G. (2006). How assessment frames student learning. In C. Bryan \& K. Clegg, (Eds.), Innovative assessment in Higher Education, pp23-36. London: Routledge.

Gibbs, G., \& Simpson, C. (2004). Condition under which assessment supports students learning. Learning and 
Teaching in Higher Education, 1, 3-31. Retrieved from www.glos.ac.uk/departments/clt/lathe1/index.cfm

Green, B. A., \& Andrade, M.S. (2010). Guiding principles for language assessment reform: a model for collaboration. Journal of English for Specific Purposes, 9, 322-334. http://dx.doi.org/10.1016/j.jeap.2010.06.003

Hattie, J., \& Timperley, H. (2007).The power of feedback. Review of Educational Research, 77, 81-112.

Jones, J. (2010). The role of assessment for learning in management of primary to secondary transition: Implications for language teachers. Language Learning Journal, 35(2), 175-191.

Keppell, M., \& Carless, D. (2006). Learning-oriented assessment: a technology-based case study. Assessment in Education: Principles, Policy \& Practice Journal, $13(2), \quad 179-191$. http://dx.doi.org/10.1080/09695940600703944

Kim, M. (2009). The Impact of an elaborated assessee's role in peer assessment in peer assessment. Assessment \& Evaluation in Higher Education, 34(1), 105-114. http://dx.doi.org/10/1080/02602930801955960

Knight, P. (2006). Assessing complex achievements. In I. McNay (Ed.), Beyond mass higher education: building on experience (pp.96-104). Maidenhead: The Society for Research in Higher Education and Open University Press.

Lee, I., \& Coniam, D. (2013). Introducing assessment for learning for EFL writing in an assessment for learning examination-driven system in Hong Kong. Journal of Second Language Writing, 22, 34-50. http://dx.doi.org/10/1080/02602930801955960

Ploegh, K. et al. (2009). In search of quality criteria in peer assessment practices. Studies in Educational Evaluation Journal, 35, 102-019. http://dx.doi.org/10.1016/j.jslw.2012.11.003

Purpura, J. (2004). Learning-oriented assessment for grammatical ability. In assessing grammar, CUP, pp.212-250.

Sadler, D. R. (2005). Interpretations of criteria-based assessment and grading in higher education. Assessment and Evaluation in Higher Education, 30(2), 175-194.

Watkins et al. (2005). Awareness of the backwash effect of assessment: A phenomenographic study of the views of Hong Kong and Swedish lecturers. Instructional Science, 33, 283-309.

\section{Appendices}

\section{Learning Oriented Assessment (LOA) in EFL/ESL Classroom}

The interview seeks to elicit information from EFL/ESL teachers about the use of learning-oriented assessment in an EFL/ESL classroom. I hope you will be kind enough to answer all of the questions in this questionnaire to the best of your knowledge and ability and provide the researcher with appropriate ideas and suggestions.

Learning-oriented assessment (LOA) deals with integrating assessment with learning. Learning-oriented assessment (LOA) represents an attempt to emphasize the learning features of assessment and promote their development. LOA has three principles: the first one is assessment tasks which should be learning tasks. The tasks should promote and stimulate learning and should mirror real-life applications of subject matter. The second principle of LOA is student involvement in assessment which could help them develop a better understanding of learning goals and engage them more actively with criteria and standards. The third principle for assessment for learning is giving students appropriate feedback which they can use in the future.

1. Do you support the idea of using learning-oriented assessment in EFL/ESL classroom? Why or why not?

2. Which one is useful for students: assessment for learning or assessment of learning? Why?

3. How can learning-oriented assessment be implemented in DELL?

4. What are the possible challenges in implementing learning-oriented assessment?

5. Do you support the idea of involving students in the assessment process through self-evaluation, peer-assessment etc.? Why or why not?

6. Why do you think assessment tasks should be learning tasks?

\section{Thank you for your cooperation}

